\title{
Percepção ambiental dos projetos de conservação dos quelônios do Tocantins, Brasil
}

O presente estudo tem por objetivo contribuir no estudo das comunidades tradicionais com a efetividade dos projetos de conservação dos quelônios e seus derivados, em especial a comunidade do distrito Café da Roça no município de Pium-TO. Utilizou-se questionário com perguntas abertas e fechadas privilegiando a opinião dos entrevistados. Identificou-se que os moradores conhecem os projetos de proteção aos quelônios, seus objetivos e quem os executa. Os moradores concordam que os quelônios precisam ser protegidos, porém não abrem mão do consumo, portanto, deve-se associar as comunidades tradicionais como participantes integrais no processo de transformação da sociedade sem perder as características culturais fundamentais que as compõe.

Palavras-chave: Comunidades Tradicionais; Projetos de Proteção; Quelônios.

\section{Environmental perception of the conservation projects of the chelonians of Tocantins, Brazil}

This study aims to contribute to the study of traditional communities the effectiveness of conservation projects of turtles and their derivatives, in particular the district of Roca coffee settlement in the municipality of Pium-TO. We used questionnaire with open and closed questions favoring the opinion of respondents. It was identified that the residents know the protection projects to turtles, their goals and who execute. Residents agree that the turtles need to be protected but not give up the consumption, should integrate traditional communities as full participants in the process of transformation of society without losing the basic cultural characteristics that compose it.

Keywords: Traditional Communities; Protection Projects; Turtles.

Topic: Conservação da Biodiversidade

Reviewed anonymously in the process of blind peer
Received: 08/05/2016

Approved: 16/10/2016

\section{Aluisio Vasconcelos de Carvalho ic}

Universidade Federal do Tocantins, Brasil

http://lattes.cnpq.br/5200758055263996

http://orcid.org/0000-0002-3793-3133

aluisiovasconcelos@gmail.com

\section{Thays Kelly Marinho Lopes}

Universidade Federal do Tocantins, Brasil http://lattes.cnpq.br/6365494618979371 thays.klm@gmail.com

\section{Adriana Malvasio}

Universidade Federal do Tocantins, Brasil http://lattes.cnpq.br/9694032726460437 malvasio@mail.uft.edu.br
Referencing this:

CARVALHO, A. V.; LOPES, T. K. M.; MALVASIO, A.. Percepção ambiental dos projetos de conservação dos quelônios do Tocantins, Brasil. Nature and Conservation, v.9, n.1, p.6-12, 2016. DOI: http://doi.org/10.6008/SPC2318-2881.2016.001.0001 


\section{INTRODUÇÃO}

A região amazônica vem sofrendo uma pressão sobre a vida selvagem, há uma década, os seres humanos trouxeram consequências que ainda perduram sobre a fauna. $O$ crescimento populacional humano contribuiu para a exploração em massa reduzindo as espécies, de outro modo, a tecnologia expandiu os meios de forrageio dos caçadores reduzindo os gastos durante a caça predatória (PERES \& PALACIOS, 2007; GODOY et al, 2010; PERES \& LAKE, 2003).

Na Amazônia, devido ao cenário atual, muitos quelônios estão seriamente ameaçados e, em muitos casos, o uso humano das espécies de tartarugas ultrapassou a capacidade de recuperação das espécies no ambiente (SCHUNEIDER et al, 2011).

Em 1979, coordenado pelo IBDF (Instituto Brasileiro do Desenvolvimento Florestal), antigo IBAMA, o Projeto de Manejo de Proteção aos Quelônios da Amazônia foi criado com o objetivo de proteger esses animais e atuar na gestão das tartarugas (manejo e consumo) porém em 1989, o atual IBAMA (Instituto Brasileiro de Meio Ambiente e dos Recursos Naturais Renováveis), dividido em várias agências federais dificultou o policiamento ambiental nas áreas vulneráveis reduzindo a efetividade na proteção das tartarugas (IBAMA, 1989).

O impacto humano sobre o ambiente local e regional vem aumentando consideravelmente, pesquisadores, planejadores e gestores são confrontados a desenvolver estratégias eficazes para preservar a biodiversidade em consonância com o crescimento populacional humano e o desenvolvimento econômico regional (SCHUNEIDER et al, 2011).

Os quelônios do gênero Podocnemis tem recebido atenção do governo para projetos conservacionistas devido a predação, consumo dos ovos, carne e derivados por parte dos ribeirinhos, comunidades tradicionais elevando o custo no mercado contrabandista (FACHÍN-TERÁN, 2003).

Atualmente, os projetos de proteção aos quelônios desenvolvidos pelos órgãos de proteção a fauna assumiram a função de reduzir a pressão antrópica, em especial, $P$. expansa e $P$. unífilis na região, através da fiscalização, monitoramento e educação ambiental. O Plano de Ação Nacional para Conservação dos Quelônios Amazônicos - PAN Quelônios Amazônicos, aprovado recentemente pela portaria №1 de 04 de abril de 2015, visa aperfeiçoar as estratégias de conservação promovendo a recuperação e uso sustentável, especialmente as espécies alvo do PAN até 2019 (IBAMA/MMA, 2016).

O objetivo deste trabalho foi avaliar a efetividade dos projetos de proteção a fauna, em especial, os quelônios do Tocantins, no distrito Café da Roça, Pium-TO, através de entrevistas realizada com os moradores da região.

\section{METODOLOGIA}

\section{Área de estudo}

O distrito Café da Roça está situado ente as coordenadas $10^{\circ} 2^{\prime} 54^{\prime \prime} \mathrm{S} 49^{\circ} 38^{\prime} 25^{\prime \prime} \mathrm{W}$. Pertencente ao município Pium-TO, compreende uma região de cerrado, onde seus habitantes dependem da pesca, do 
comércio e da agricultura. O município de Pium-TO, encontra-se a $130 \mathrm{~km}$ da capital Palmas-TO possui cerca de 7.357 habitantes (IBGE, 2015). Na região está inserida as unidades de conservação APA Ilha do BananalCantão, o Parque Estadual do Cantão - PEC e Parque Nacional do Araguaia.

\section{Coleta e Análise de Dados}

A coleta dos dados baseou-se na metodologia de Michel (2005), utilizando observação individual a fim de buscar aspectos manifestados involuntariamente pelos entrevistados e entrevista semiestruturada, com perguntas abertas e fechadas, buscando informações acerca dos elementos socioculturais e econômicos da população pesquisada.

Gil (1999), caracteriza as pesquisas de levantamento cujas pessoas que se pretende conhecer, utilizando interrogações diretas, verificando também seu comportamento. Procede-se basicamente, com a solicitação de informações a um determinado grupo de pessoas acerca do problema estudado, analisando quantitativamente para obter conclusões através dos dados coletados.

Foi selecionado aleatoriamente moradores da região, encontrados nas ruas, na escola e nas residências do distrito Café da Roça. Por possuírem influência devido à proximidade do rio Javaés, os moradores conhecem a região do Parque Nacional do Araguaia e possui o hábito da pesca de quelônios como fonte de renda e de alimento.

Os roteiros foram elaborados com perguntas abertas, para que o entrevistado pudesse emitir sua opinião, e fechadas, dando-lhe a múltipla escolha, revelando as diversas facetas de um mesmo assunto (MARCONI \& LAKATOS, 2008). As perguntas contidas no questionário buscaram-se os elementos socioeconômicos da população (nome, idade, sexo, naturalidade, profissão, no de pessoas na residência, renda familiar, escolaridade), culturais (consumo de quelônios e derivados) e ambientais.

Adotou-se uma linguagem comum devido a alguns entrevistados não dominarem a linguagem acadêmica, buscando de forma clara e objetiva obter os resultados, garantindo o anonimato e sigilo dos envolvidos no processo, dando-Ihe a segurança de ser apenas um trabalho acadêmico.

No distrito Café da Roça selecionou-se 20 indivíduos, acima de 18 anos, pessoas da comunidade que exerciam algum papel. Os questionários foram aplicados em outubro, anotados e arquivados para análise mais profunda a partir dos resultados obtidos durante a pesquisa. A análise consistiu na tabulação das informações obtidas em planilhas do Microsoft Excel 2010 e elaboração de gráficos a partir dos dados obtidos na entrevista, as respostas dos entrevistados foram transcritas para arquivo de texto do Microsoft Word 2010.

As informações obtidas pelas entrevistas dos moradores do distrito Café da Roça foram transcritas para o Microsoft Word 2010, os dados foram tabulados e transformados em gráficos para melhor compreensão dos resultados quanto ao perfil socioeconômico, consumo de quelônios e derivados, entre outros. Para análise dos dados, consideraram-se todos os entrevistados, sabendo que estes moram no assentamento há muito tempo, portanto conhecem melhor a região e os costumes. 


\section{RESULTADOS}

\section{Perfil dos entrevistados}

Os 20 entrevistados, das quais 14 eram mulheres e 06 homens, possuíam idade entre 19 a 65 anos, a maioria natural do Tocantins. Todos exercem alguma atividade trabalhista entre eles comerciante, lavrador e professor, com renda familiar mensal de 1 a 2 salários mínimos na maior parte dos interlocutores (60\%), com 02 a 09 pessoas no grupo familiar.

Todos os entrevistados afirmaram que utilizam outra atividade para complementar a renda, como a pesca. Cerca de $40 \%$ dos entrevistados afirmaram morar há mais de 20 anos na região, trabalhando muitas vezes, com lavoura e criação de animais. A maioria dos entrevistados (30\%) completaram o ensino médio e em sua minoria (5\%) são considerados analfabetos.

\section{Percepção dos Entrevistados}

Verificou-se que $45 \%$ dos entrevistados não conhecem o projeto quelônios da llha do Bananal na região. Os interlocutores que afirmaram conhecer ou mesmo já ter ouvido falar do projeto, 50\% disseram não saber os objetivos do projeto quelônios da Ilha do Bananal. Dessa mesma forma, perguntou-se aos entrevistados se tinham o conhecimento de quem executava o projeto, apenas $15 \%$ afirmaram saber que era responsável pelo projeto.

Foi questionado sobre a proteção dos quelônios na região, 95\% dos entrevistados concordaram que os quelônios precisam ser protegidos. Perguntou-se aos interlocutores se eles tinham conhecimento de como ocorre o manejo e proteção dos quelônios na llha do Bananal, 30\% responderam que sim, $50 \%$ não sabiam e $15 \%$ responderam que sabiam mais ou menos e $5 \%$ não opinou/respondeu.

Os entrevistados afirmaram saber a época de reprodução dos quelônios da região (30\%), outros afirmaram não conhecer o período reprodutivo (65\%) e 5\% não opinou/respondeu. Os que afirmaram saber sobre o período reprodutivo dos quelônios disseram que ocorria nos meses de "junho a agosto", "outubro", "setembro a dezembro", " setembro a outubro", "agosto a setembro".

Dos entrevistados, $80 \%$ afirmaram que trabalhariam no manejo e proteção desses animais já que $40 \%$ afirmaram que os estoques (quantidade) naturais desses animais na região estão baixos, $50 \%$ não sabem e somente $10 \%$ responderam que existe uma grande quantidade de quelônios na região.

A fiscalização por parte dos órgãos de proteção ambiental existe na região segundo os entrevistados (65\%) enquanto que 35\% falaram não ter fiscalização na região. Os órgãos de proteção ambiental mais citados foram o NATURATINS, IBAMA e Polícia Ambiental.

\section{DISCUSSÃO}

Os entrevistados nesse estudo realizavam alguma atividade trabalhista, na maioria, servidores do município de Pium-TO. Além disso, desenvolvem outras atividades para complementar a renda como a pesca, 
criação de animais e agricultura de subsistência, essas outras atividades, associadas ao tempo de vivência na região.

Foi observado que $45 \%$ dos interlocutores não conhecem o projeto quelônios da Ilha do Bananal. Criado em 1998 pelo IBAMA com parceria da Universidade do Tocantins (UNITINS) por meio do Centro Nacional de Quelônios (CENAQUA), suas atividades iniciaram em 2000, mas sua sede foi abandonada devido a conflitos com indígenas da região. Em 2001, as atividades foram retomadas, porém com sede no encontro do riozinho com rio Javaés realizando o trabalho de manejo dos ninhos de $P$. expansa em cinco praias do rio Javaés.

Embora 50\% dos entrevistados afirmarem não conhecerem os objetivos do projeto, ainda existe um efetivo empenho entre os órgãos de proteção no projeto atual. Com o intuito de estimar a estrutura populacional, manejo e preservação das espécies $P$. expansa (Tartaruga da Amazônia) e $P$. unifilis (Tracajá), o projeto conta também com outros programas como o Projeto Quelônios do Tocantins. Embora estas espécies estejam listadas no International Union for Conservation of Nature (IUCN), P. expansa é classificada atualmente como baixo risco à extinção mas carece de programas e ações de conservação enquanto que Podocnemis unifilis está classificada como espécie vulnerável à extinção devido à pressão antrópica em suas populações aumentando sua exploração direta e reduzindo seu habitat (IUCN, 2015).

Os entrevistados (95\%), concordaram que os quelônios precisam ser protegidos. A exploração de quelônios aquáticos é uma prática antiga, seguida até hoje através das gerações indígenas e ribeirinhos da bacia amazônica. Segundo a lei de proteção a fauna, 5.197/67, a prática não é proibida permanentemente desde que o agente possua licença da autoridade competente (DAL'AVA, 2003; BRASIL,1967). A Lei 9.605/98Crimes Ambientais ressalta a exceção para as populações humanas que caçam para sobreviver, por necessidade, saciar a fome da família ou do agente (BRASIL, 1998).

O manejo dos quelônios aliado ao planejamento de estratégias, implementação de programas efetivos tendem a diminuir a pressão antrópica sobre a espécie (PEZZULTI et al, 2003, 2010; FACHÍN-TERÁN et al, 2004).

Embora uma pequena parcela dos entrevistados dissera que sabiam o período reprodutivo (30\%), afirmaram que os meses de reprodução do quelônio aquático variavam entre os meses de junho a dezembro. A espécie Podocnemis expansa desova entre os meses de setembro/outubro podendo variar de acordo com sua distribuição geográfica, e a eclosão dos filhotes ocorre nos meses de novembro/dezembro (FERREIRA JÚNIOR e CASTRO, 2003). Evidentemente, a exploração dos ovos e das tartarugas matrizes tornam-se mais intenso pela facilidade de captura dos mesmos.

Não obstante, $80 \%$ dos entrevistados disseram que trabalhariam no manejo e proteção desses animais devido aos estoques naturais estarem se esgotando na região segundo $40 \%$ dos interlocutores. $\mathrm{Na}$ bacia amazônica a Tartaruga da Amazônia é considerado uma iguaria, isso resulta na superexploração da espécie e contrabando no mercado negro tornando ineficaz as ações de proteção pelo governo (VOGT 2001, 2008; SCHUNEIDER et al, 2009, 2011). 
Os órgãos de proteção ao meio ambiente trabalham na fiscalização para o controle da exploração da espécie na região segundo os entrevistados (65\%), dentre eles foram citados o IBAMA, NATURANTINS e Polícia ambiental. Foram citados ainda palestras de educação ambiental no assentamento para conscientizar a população da vulnerabilidade da espécie na região. O impacto humano sobre os quelônios seja local ou regional necessita de pesquisadores, planejadores e gestores para desenvolver estratégias na preservação da biodiversidade em face de crescimento da população humana e do desenvolvimento econômico (SCHUNEIDER et al, 2011).

Segundo Fachín-Teran (2005) a participação comunitária assume uma estratégia positiva na preservação das espécies ameaçadas reduzindo o depleciação da espécie na região, o caso de Mamirauá é um exemplo para o problema diante dos esforços de manter a população como protagonista no manejo e proteção dos quelônios aquáticos. De acordo com Carvalho (2015) o governo deve centralizar a população como integrante principal nas políticas públicas tornando o conhecimento tradicional, as leis vigentes de proteção da biodiversidade corresponsáveis para a proteção ambiental local.

Envolver todos pode contribuir para o manejo adequado das populações naturais, de um lado as pessoas atuando como protagonistas no processo de conservação da fauna e do outro o poder público capacitando os envolvidos em prol de uma sociedade mais preocupada com o desenvolvimento sustentável.

\section{AGRADECIMENTOS}

Este trabalho foi apoiado pela Agência Brasileira Federal de Apoio e Avaliação da Educação Superior (Coordenação de Aperfeiçoamento de Pessoal de Nível Superior - CAPES). Agradecemos ao Instituto Brasileiro do Meio Ambiente e dos Recursos Naturais Renováveis (IBAMA) e Universidade Federal do Tocantins por permitir que este estudo fosse possível.

\section{REFERÊNCIAS}

BRASIL. Lei n. 5197 de 3 de janeiro de 1967. Dispõe sobre a proteção à fauna e dá outras providências. Brasília: DOU, 1967.

BRASIL. Lei $\mathbf{n} .9605$ de 12 de fevereiro de 1998. Dispõe sobre as sanções penais e administrativas derivadas de condutas e atividades lesivas ao meio ambiente, e dá outras providências. Brasília: DOU, 1998.

CARVALHO, A. V.. Educação Ambiental no Desenvolvimento Sustentável Municipal. DESAFIOS: Revista Interdisciplinar da Universidade Federal do Tocantins, v.2, n.1, p.97-108, 2015.

DAL'AVA, F.. A evolução da legislação brasileira de proteção a fauna. In: RENCTAS. Animais silvestres: vida à venda. 2 ed. Brasília: Dupligráfica, 2003. p.145-172

FACHÍN-TERÁN, A.; VOGT, R. C.; THORBJARNARSON, J. B. Patterns of use and hunting of turtles in the Mamirauá Sustainable Development Reserve, Amazonas, Brazil. In: SILVIUS, K. M.; BODMER, R. E.; FRAGOSO, J. M. V.. People in Nature: Wildlife Conservation in South and Central America. Columbia University Press, 2004. p.362-377
FACHÍN- TERÁN, A.. Participação Comunitária na Preservação de praias para reprodução de quelônios na Reserva de Desenvolvimento Sustentável Mamirauá, Amazonas, Brasil. UAKARI, v.1, n.1, p.9-18, 2005.

FACHIN-TERÁN, A.. Preservação de quelônios aquáticos com participação comunitária na Reserva de Desenvolvimento Sustentável Mamirauá, Amazonas, Brasil. In: CAMPOS-ROZO, C.; ULLOA, A.. Fauna Socializada: tendenciasenel manejo participativo de la fauna en América Latina. Bogotá: Fundación Natura; MacArthur Foundation; Instituto Colombiano de Antropología e Historia, 2003. p.145-176

FERREIRA JÚNIOR, P. D.; CASTRO, P. T. A.. Geological control of Podocnemis expansa and Podocnemis unifilis nesting areas in Rio Javaés, Bananal Island, Brazil. Acta Amazônica, v.33, n.3, p.445-468, 2003.

GIL, A. C... Métodos e técnicas de pesquisa social. São Paulo: Atlas, 1999. 
GODOY, R.; UNDURRAGA, E. A.; WILKIE, D.; REYES-GARCIA V.; HUANCA, T.; LEONARD, W. R.; MCDADE, T.; TANNER, S.; VADEZ, V.. The effect of wealth and real income on wildlife consumption among native Amazonians in Bolivia: estimates of annual trends with longitudinal household data (20022006). Animal Conservation, v.13, n.3, p.265-274, 2010.

IBAMA. Instituto Brasileiro do Meio Ambiente e dos Recursos Naturais Renováveis. Projeto Quelônios da Amazônia: Manual Técnico. Brasília: MMA, 1989.

IBAMA. Instituto Brasileiro do Meio Ambiente e dos Recursos Naturais Renováveis. Plano de ação nacional para conservação dos quelônios amazônicos. Brasília: MMA, 2016.

IUCN. Tortoise \& Freshwater Turtle Specialist Group: Podocnemis expansa. The IUCN Red List of Threatened Species, 1996.

MARCONI, M. A.; LAKATOS, E. V.. Fundamentos da metodologia científica. 6 ed. São Paulo: Atlas, 2008.

MICHEL, M. H.. Metodologia e pesquisa científica em ciências sociais: um guia prático para acompanhamento da disciplina e elaboração de trabalhos monográfcos. São Paulo: Atlas. 2005.

PERES, C. A.; LAKE, I. R.. Extend of nontimber resource extraction in tropical forests: accessibility to game vertebrates by hunters in the Amazon Basin. Conservation Biology, v.17, n.2, p.521-535, 2003.
PERES, C. A.; PALACIOS, E.. Basin-wide effects of game harvest on vertebrate population densities in Amazonian forests: Implications for animal-mediated seed dispersal. Biotropica, v.39, p.304-315, 2007.

PEZZUTI, J. C. B.. Ecologia e Etnoecologia de Quelônios no Parque Nacional do Jaú, Amazonas, Brasil. Tese (Doutorado em Ecologia) - Universidade Estadual de Campinas, Campinas, 2003.

PEZZUTI, J. C. B.; PANTOJA-LIMA, J.; SILVA, D. F.; BEGOSSI, A.. Uses and taboos of turtles and tortoises along Rio Negro, Amazon Basin. Journal of Ethnobiology, v.30, n.1, p.153168, 2010.

SCHNEIDER, L.; BELGER, L.; BURGER, B.; VOGT, R. C.. Mercury bioaccumulation in four tissues of Podocnemis erythrocephala (Podocnemididae: Testudines) as a function of water parameters. Science of the Total Environment, n.407, p.1048-1054, 2009.

SCHNEIDER, L.; FERRARA, C. R.; VOGT, R. C.; BURGER J.. History of Turtle Exploitation and Management Techniques to Conserve Turtles in the Rio Negro Basin of the Brazilian Amazon. Chelonian Conservation and Biology, v.10, n.1, p.149-157, 2011.

VOGT, R. C.. Tartarugas da Amazônia. Manaus: INPA, 2008.

VOGT, R. C.. Turtles of the Rio Negro. In: CHAO, N. L.; PETRY, P.; PRANG, G.; SONNESCHIEN, L.; AND TLUSTY, M..

Conservation and Management of Ornamental Fish Resources of the Rio Negro Basin, Amazonia, Brazil. Manaus: EdUFAM, p.245-262, 2001. 